\title{
Wind Turbine Development Status and Advices in China
}

\author{
Wenyi Liu ${ }^{* 1, a}$, Zhenfeng Wang ${ }^{2, b}$ \\ ${ }^{1}$ School of Mechanical and Electrical Engineering, Xuzhou Normal University, Xuzhou, 221116, \\ China \\ ${ }^{2}$ College of Mechanical and Electrical Engineering, Henan Agricultural University, Zhengzhou \\ 450002, China. \\ aliuwenyi1984@yahoo.com.cn, bzhenfengking@163.com
}

Keywords: Wind turbine, Energy, Status, Install capacity

\begin{abstract}
Aimed at the analysis of wind turbine development status in 2010, this paper discussed the wind turbine capacity status and manufacturers in China. Through the detail analysis in the wind turbine development status, some problems have been discussed such as planning imbalance between country and local governments, coordinate between wind energy and other energy, performance of wind turbine, etc. Aimed at above problems in the wind turbine development, this paper gives some corresponding advices to resolve these problems.
\end{abstract}

\section{Introduction}

As a rapidly developed renewable energy resource, wind energy has obtained widely attention around the world in the last few years $[1,2]$. As shown in the statistic data in Global Wind Energy Council (GWEC) 2010, the development speed in 2010 of the wind power area is much slower compared to the rapid development in 2009 and last 10 years. The wind turbine new install capacity in 2010 is reduced about $6.2 \%$ compared to the data in 2009 [3, 4].

In the year 2006, the wind turbine install capacity in China had already reached to $26000 \mathrm{MW}$, which made China to be one of the main wind turbine markets following the Europe and America. Since 2007, the development speed of wind turbine install capacity in China increased fast. In 2008, an additional installed capacity $6.3 \mathrm{GW}$ of wind power were installed in China, bringing the total installed capacity to $12.2 \mathrm{GW}$. The install capacity rate is $108 \%$ compared to the data in 2007 . The off-shore wind turbine also developed fast. In the provinces Inter monggol , Xinjiang, Liaoning, Shandong and Guangdong, the wind energy resource is abundant and the corresponding wind industry is developed in a high speed $[5,6]$.

This paper discusses the wind turbine capability status and the manufacturer status in China, analyze the problems nowadays in the wind turbine development and give some corresponding advices following the analysis.

\section{Wind turbine capacity status in China}

In the year 2010 in China, the new installed wind turbine number is 12904MW (not include Province Taiwan), the capacity is $18927.99 \mathrm{MW}$ and the growing rate is $37.1 \%$ compared to the data in 2009. As shown in Fig. 1, the total wind turbine install number is $34485 \mathrm{MW}$, the total capacity is 44733.29MW and the growing rate is nearly $73.3 \%[7]$.

The new wind turbine installed capacity in China is now the first one in the world, which takes up $46.1 \%$ of the world wide new installed capacity. The world wide new investment on the new cleaning energy in 2010 is about 243 billion, which is increased in 30\%. Among this, China wind turbine market is keeping the rapid development speed. At the same time, China becomes the biggest wind turbine device manufacture country benefit from the rapid wind investment [8]. 


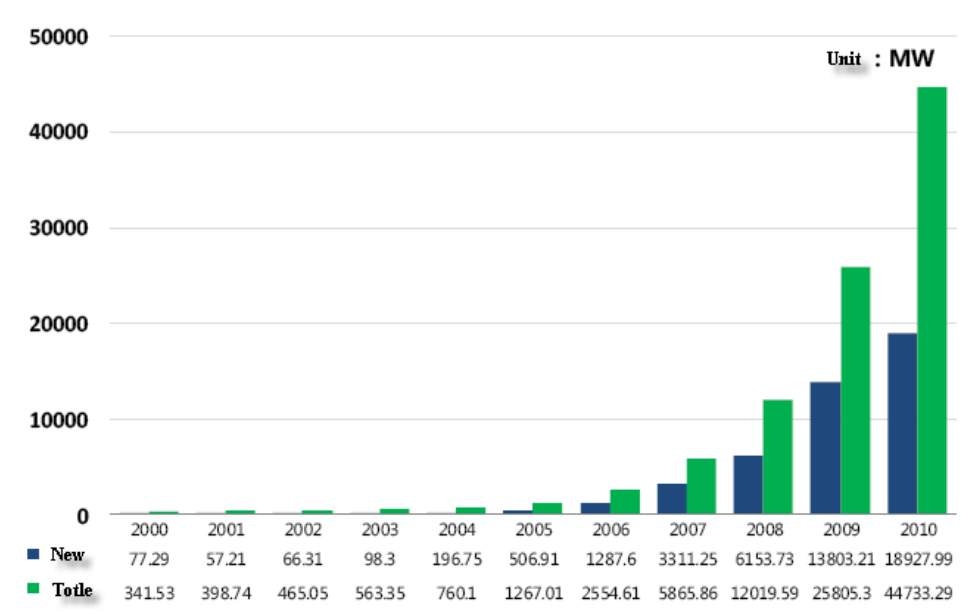

Fig. 1 Wind turbine capital between 2000 to 2010 (MW)

According to the China Wind Power Outlook 2010, in 2020 the wind turbine total install capacity will achieve $230,000 \mathrm{MW}$ which is amount to 13 times of the Sanxia power station. The total generate electricity will achieve 464.9Billion $\mathrm{KW} / \mathrm{h}$, which can replace about 200 heat-engine plants. This means that the wind turbine capacity need to be increased at the number of $12000 \mathrm{MW}-15000 \mathrm{MW}$ every year [9]. The worldwide total value of wind power out-put is about 57 billion dollars, in which the on-land wind turbine number is declined fast. The out-shore wind turbines and the mini-type wind turbine market is growing up fast, for the reason of the pulling of the Chinese wind turbine market.

As shown in Fig. 2, 1500KW type wind turbine has been gained more attention in the year 2009, occupy about $67.05 \%$ of the new installed capacity. Both the bigger and smaller turbines are not too much in the new installed number. According to the wind turbine government draft, China will construct about 7 big MW group wind turbine base in Gansu, Xinjiang, Hebei, Jilin, Inter monggol, Jiangsu province [10]. The nation power office ensured the 10000-MW wind turbine base plan. After the construction of these bases, the wind power install capacity will achieve to about 100000 MW. According to the planning of the nation power grid, these 7 wind turbine bases will be finished in 2020, in which till 2015 about 58080MW will be finished, and in the year 2020 about $90170 \mathrm{MW}$ will be finished. The install capacity will occupy $60 \%$ in the whole Chinese wind market.

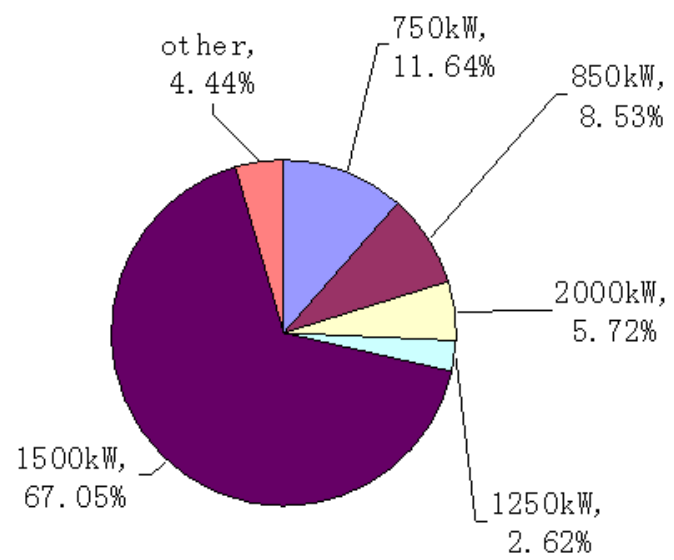

Fig. 2 Different type wind turbine distribution in the 2009 new installed capacity (Computed in installed wind number)

\section{Manufacturers}

With the rapid growth of Chinese wind industry, there has also been an increase in wind researches in various regions in China over the last few years. Manufacturers in wind turbine are growing fast, too. In 2009, the manufacturer number which has the new install capacity over 100MW is about 19 , in which the Huarui(3495 MW), Jinfeng(2722 MW) and Dongqi(2035.5MW) are over 1000MW and the install capacity is occupy about $59.7 \%$ in the 2009 new install capacity[11]. Table 1 shows the new install capacity in some big manufacturers in China in the year 2010. 
Table 1 New installed capacity in every manufacturer in China

\begin{tabular}{llll}
\hline Install scale (MW) & Name & New install (MW) & Percent (\%) \\
\hline \multirow{3}{*}{1000} & Huarui & 3495 & 25.3 \\
& Jinfeng & 2722 & 19.7 \\
& Dongqi & 2035.5 & 14.7 \\
\hline & Lianhe & 768.5 & 5.4 \\
& Mingyang & 748.5 & 5.4 \\
& Vestas & 608.75 & 4.4 \\
& Xiangdian & 454 & 3.3 \\
& GE & 322.5 & 2.3 \\
& Suzlon & 293 & 2.1 \\
& Gamesa & 276.25 & 2.0 \\
& ShanghaiDianqi & 274.25 & 2.0 \\
& Yunda & 260.75 & 1.9 \\
\hline \multirow{5}{*}{$100-200$} & REpower & 198 & 1.4 \\
& Huachuang & 163.5 & 1.2 \\
& Beichong & 138 & 1.0 \\
& Yuanjing & 136.5 & 1.0 \\
& Nancheshidai & 127.05 & 0.9 \\
& Huayi & 119.46 & 0.9 \\
\hline other & Nordex & 111 & 0.8 \\
\hline Total & & 551.2 & 4.0 \\
\hline
\end{tabular}

Source: China wind energy association (CWEA) [7]

The wind power industry planning not only drives the construction of the wind turbine bases, but also encourages the development of the wind turbine manufacturers. The wind turbine manufacturers which are in the number 10 wind turbine manufacturers and the number 3 wind turbine manufacturers develop extremely well. There are about 82 manufacturers which can produce whole wind turbines. In which the state-belong manufacturer is about 39, self-operate manufacturer is 24 , joint venture manufacturer is 9 . According to the development scale of these manufacturers, they can be divided in to 5 types:

Type one: There are 3 manufacturers which can produce multitudinous whole wind turbines. Huarui (in 2008 installed 1400MW, 2009 installed 3490MW), Jinfeng (in 2008 installed 1130MW, 2009 installed 2270MW), Dongqi (in 2008 installed 1050MW, 2009 installed 2030MW). These three manufacturers can produce at least 1000 wind turbines every year.

Type two: There are about 10 manufacturers which have quantity production capacity in wind turbine industry.

Type three: There are about 9 manufacturers which have little quantity production capacity in wind turbine industry.

Type four: There are some manufacturers who are doing some experiments in whole prototype test or design and test-manufacture. The industrialization is still need some practicable work.

Type five: Some manufacturers have mature design and manufacture techniques, and have the ability to produce some part of the wind turbine. Most of there manufacturers are foreign individual proprietorship type.

\section{Problems in wind turbine development}

Planning imbalance between country and local government. The local government establishes the wind turbine planning mainly according to the local wind resource situation, without the consideration of the power structure and wind market of the whole wind power system. Especially in drawing up the big wind power farm or wind base, the local planning is always bigger than the country whole planning. Therefore, it needs guiding work in the real policy planning. 
Coordinate between wind energy and other energy. The wind source has the characteristics of intermittent, randomness and uncontrollability, which leads to the wind power generation has the characteristics that random and local against pitch peak. These bring the difficulties that affect the wind generation safe operation. The digestion scale of the power system to wind energy mainly depends on the reasonable planning and resource optimal configuration. In China the power structure is mainly coal electricity (about 75\%). In some areas the hydroelectric install are mainly runoff power station. In these reasons, the digestion ability of the power grid of the wind power has been restricted in most areas.

Lack of reasonable planning and comprehensive utilization. For example, in some provinces in the land wind farm are mainly local on the costal intertidal zone. For these areas belong to the long coast, the frequent intertidal zone inning will drive the established wind farm far away from the coast line. If these areas begin to develop the industry, the wind speed in the farm will be reduced. Especially if the importing projects have high pollution enterprises, the industrial waste gas will influence the performance and lifetime of the wind turbines, increase the maintenance cost and waste the wind farm investment. In addition, the wind farm occupies big area of land and need unified plan, combine the local economic growth to develop tourism, aquaculture or other resources.

Wind power synchronize and close problems. Since the year 2008, in some big wind power provinces, such as Inter monggol, Gansu, Hebei, some situation have been appeared that the whole power grid restrict the wind power. Most wind power developers exist the wind power wasting phenomenon. Till the end of year 2008, the whole wind install capacity of the 48 wind farm is $4400 \mathrm{MW}$, which is bigger than the $70 \%$ of the first 7 manufacturers' whole install capacity. However, because of the power restriction of the power grid, these 48 wind farms' power lost is about 3700 Million KW/h. In 2009 and 2010, the wind power waste problem is still much serious, which need to be solved eagerly.

Performance of the wind turbine. The performance of wind turbine affects not only the safe stable operation, but also the safe of the power grid and payoff of the wind generation manufacturers. Manufacturers from abroad always test the wind turbine strictly before the wind turbine access to markets. Generally, the test includes the three progresses: whole machine test, prototype machine test run and third party test. However, the quantity production phenomenon in China brings the uncertain risk to the electricity generate enterprises. The wind turbines in quantity production have shown some problems, such as hub crack, bearing problems, gear-box problems and generator problems, etc.

In addition, even some wind turbine equipments have performance problem, the wind farm usage ratio is still not very high. In the last few years, the government and manufacturers have planned some good policies to raise the performance of the wind turbine, and obtained some good results.

Whole wind turbine design. At the beginning the manufactures of the whole wind turbine mainly depend on the abroad technique or cooperation design. The self-design capability of the whole wind turbine is still weak. The wind turbine suitable design software is also need to be developed.

\section{Advices}

Aimed at above problems in the wind turbine development, we can conclude some corresponding advices as shown below.

The differences in some wind turbine key components. Some MW-type wind turbine components such as bearings and gears are in the little quantity production stage. The whole wind turbine control system is still in the test. These productions are mainly dependent on the import from some other countries. The reliability of some key parts such as gear-box and generators need to be enhanced. The development of the wind blade is on the self design stage. These need some key technologies to be further researched. 
Commonality research tests in wind turbine industry. In some countries such as USA, German, Denmark and Spain, the national wind turbine industry research test has been established some years before. These tests can be used for gear-box, blade and the transmission ability. However, in China there is on the starting in these researches, which restrict the continue development of the wind technology.

Off-shore wind turbine devices. There are mainly on-shore wind turbines been developed in the last few years in China. The off-shore wind turbine develops much slower than the on-shore wind turbine. In other words, the development is on the first step. On some aspects, such as sea wind sources research, off-shore wind turbine technologies, near sea wind turbine market construction, wind turbine wording maintenance, some corresponding techniques need to be deeply studied.

Wind turbine design and construct. Nowadays, the design of wind turbine in China mainly depends on the abroad commerce software, which is not fit for the real complex landform in China. Therefore, the design error is serious. On the other hand, the $1000 \mathrm{MW}$ wind turbine bases to be constructed have no precedent to be followed. The off-shore wind turbine design is also need technique support.

Wind power source analysis. The self-design software about wind power field design and wind source analysis needs to be studied. Now there lacks some mature corresponding software in China and the main software are depend on the import. There lacks advanced wind power measure and control system and short time power forecast system in China, and the wind power adopt technique of the power grid is also lower than some other countries.

\section{Conclusions}

Wind energy has obtained widely attention around the world and developed fast in the past few years not only in China but also in other countries. Along with the fast increasing of the whole wind turbine install capacity and new install capacity, there are also some problems in the development. Based on the analysis of the wind turbine development status in China in 2010, some problems and corresponding advices have been listed in this paper. Wind turbine planning and policy should be suitable with the local wind energy and industry construction. The wind power source analysis software and wind turbine design software should be supported by some suitable techniques.

\section{Acknowledgments}

This research was supported by the Scientific research support project for teachers with doctor's degree, Xuzhou normal university, China (Grant No. 11XLR15), the National Science Foundation for Young Scientists of China (Grant No. 71001111), the Humanity and Social Science Youth foundation, Ministry of Education, China (Grant No. 09YJC630246). First Author is corresponding author.

\section{References}

[1] World Wind Energy Report 2008, 2009, World Wind Energy Association WWEA

[2] 2009 Deep Research Report on China wind turbine blade Industry, 2009

[3] Research Report of Chinese Wind Power Industry, 2009

[4] Liu Wenyi; Tang Baoping; Jiang Yonghua. Status and problems of wind turbine structural health monitoring techniques in China. Renewable Energy. 2010, 35(7): 1414-1418.

[5] Germanischer L. Wind Energy, GL Wind. Possible Wind Turbine Damage. http://www.gl-group.com/industrial/glwind/3780.htm

[6] Tang Baoping, Liu Wenyi, Tao Song. Wind turbine fault diagnosis based on Morlet wavelet transformation and Wigner-Ville distribution. Renewable Energy. 2010, 35(12): 2862-2866. 
[7] China wind energy association (CWEA). 2010 China wind installed capacity statistics.

[8] China wind power info-net. http://www.cnwp.org.cn/ziliao/show.php?itemid=490

[9] New installed capacity in China. http://www.cnwp.org.cn/news/show.php?itemid=4147

[10] China wind power info-net. http://www.cnwp.org.cn/news/show.php?itemid=5144

[11] China wind energy association (CWEA). 2009 wind machine manufacturing market structure in China and its development tendency. Wind Energy. 2010. 1:34-37.

[12] China wind energy association (CWEA). 2009 China wind installed capacity statistics. Wind Energy.2010.1:27-33

[13] China wind power info-net. http://www.cnwp.org.cn 